\title{
Erratum to: Evaluation of Thermocyclic Oxidation Behavior of HVOF-Sprayed NiCrFeSiB Coatings on Boiler Tube Steels
}

M.R. Ramesh, S. Prakash, S.K. Nath, Pawan Kumar Sapra, and N. Krishnamurthy

\section{Erratum to: J Therm Spray Tech \\ DOI 10.1007/s11666-010-9605-x}

We regret that the original article was published with an incomplete Figure 10. Figure 10 should have been published as below.

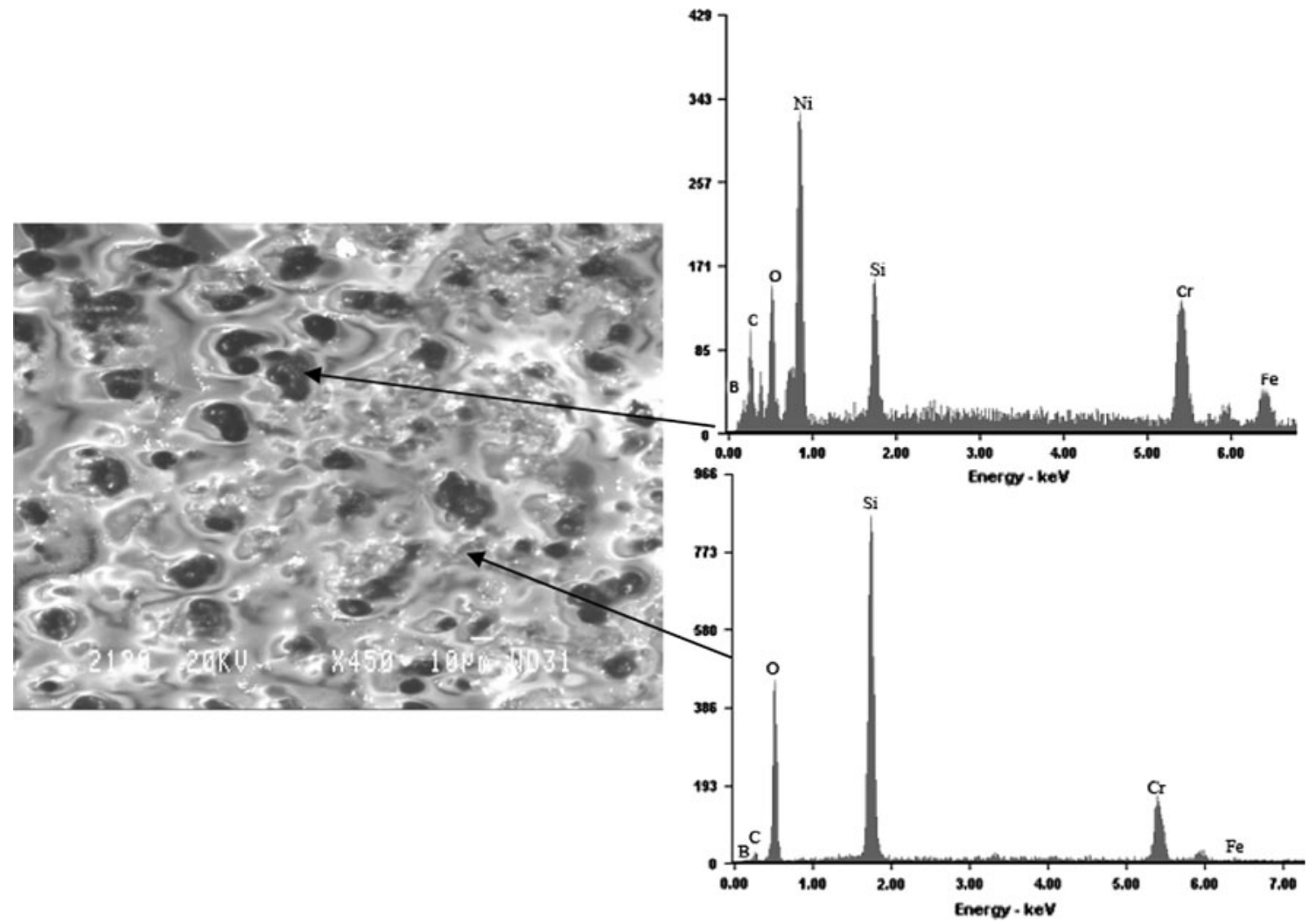

Fig. 10 Surface scale morphology and EDAX point analysis for oxidised NiCrFeSiB-coated GrA1 steel

The online version of the original article can be found under doi:10.1007/s11666-010-9605-x.

M.R. Ramesh, Reva Institute of Technology and Management, Kattigenahalli, Yelahanka, Bangalore 560 064, India; S. Prakash, S.K. Nath, and Pawan Kumar Sapra, Metallurgical and Materials Engineering Department, Indian Institute of Technology Roorkee, Roorkee 247 667, India; and N. Krishnamurthy, Sri Venkateshwara College of Engineering, Vidyanagar, Chikkajala, Bangalore 562 157, India. Contact e-mail: mr_ramesh@rediff mail.com. 